\title{
Chemical Sensors for Heavy Metals/Toxin Detection
}

\author{
Larisa Lvova \\ Department of Chemical Science and Technologies, University “Tor Vergata”, via della Ricercha Scientifica 1, \\ 00133 Rome, Italy; larisa.lvova@uniroma2.it
}

Received: 20 February 2020; Accepted: 21 February 2020; Published: 22 February 2020

\section{Introduction}

Nowadays, the huge release of pollutants into the environment has become a significant problem in many countries and entire regions. The growing industrial impact and incorrect preservation of wastes are among the main factors causing toxins and multimetal contamination. The high content of these pollutants in soil, air, and drinking water cause their consecutive accumulation in humans and this phenomenon has been connected to the insurgence of allergies, tumors, and other pathologies. This emphasizes the necessity of a careful detection and frequent analysis of heavy metals and toxins content in order to protect humans and the environment against risks caused by them. For this reason, the present Special Issue is focused on the novel achievements in analytical procedures, in terms of the development of chemical sensors and the application of related analytical methods for heavy metals and toxins assessment.

\section{The Special Issue}

The Special Issue contains the collection of nine original contributions: one communication, three research papers, and five reviews all dedicated to the development and application of chemical sensors for heavy metals and/or toxins detection. The contribution of Hakonen and Strömberg [1] proposes a low-cost method based on dye/ionophore $/ \mathrm{Pb}^{2+}$ ions co-extraction from water phase with a further probe decolorization (and fluorescence decline) for highly sensitive in-situ lead measurements at sub-ppb levels. The review of Evtugyn and Hianik [2] describes the modern electrochemical biosensors based on immunological reactions and aptamers for the determination of mycotoxins, the most common contaminants negatively influencing human health. The contribution from the group of Prof. Riul, Jr. [3] represents a comprehensive review on the application of Electronic Tongue multisensory systems for the detection of heavy metals and toxins in water, soil, and food. Recently developed low molecular weight probes (LMFP) for fluorescence sensing of the $\mathrm{Zn}^{2+}, \mathrm{Cd}^{2+}$, and $\mathrm{Hg}^{2+}$ metals upon their coordination are carefully reviewed in the contribution of Prof. Wallace group [4]. The main benefits and drawbacks, as far as the future perspective of LMFP development are discussed. The review of Kuchmenko and Lvova [5] provides a selection of the last two decades publications on applications of the piezoelectric quartz resonators-based sensors and multisensory arrays for environmental monitoring and foodstuff analysis; the particular case study dedicated to the Quartz Crystal Microbalance (QCM) sensors array implementation for heavy metal ions activity evaluation in water vapors is reported. In the review of Tan, Ibsen and Tjin [6], recent efforts on optical fiber refractometer-based metal ion sensors development are reported along with the different technologies and methods involved, and notable advancements in this area are discussed.

Finally, three research articles are devoted to the development of novel sensing materials for potentiometric and optical sensors for heavy metals detection. The study of potentiometric cross-sensitive sensors with polyvinyl-chloride plasticized membranes based on modified ligands originally developed for liquid extraction is reported in the research article of Khaydukova and colleagues [7]. The possibility to vary sensitivity and selectivity patterns of sensors was shown in 
respect to a particular application, and for rare earth cations detection in particular. Prof. S. Kumar together with colleagues [8] reports on the selective colorimetric and fluorescence probe for $\mathrm{Hg}^{2+}$ ions detection using a benzothiazolinic spiropyran dye. The presence of mercuric ions in water was assessed through the dye disaggregation mechanism and displayed both naked eye visible color change (pink to colorless) and fluorescence response; experimental results were supported with DFT studies. The paper by Prof. Belobrov et al. [9] describes the disposable microfluidic luminescent biosensor based on enzyme inhibition for rapid assessment of heavy metals in waters with a selectivity comparable to commercial luminometers.

Of course, this research collection does not cover the whole range of advancements in the field; however, it contains new methods and ideas for metallic pollutants and toxins detection, and this will hopefully inspire further interest of scientific community to this topic and new research efforts in this area.

Conflicts of Interest: The author declares no conflict of interest.

\section{References}

1. Hakonen, A.; Strömberg, N. Fluorescence and Naked-Eye Detection of $\mathrm{Pb}^{2+}$ in Drinking Water Using a Low-Cost Ionophore Based Sensing Scheme. Chemosensors 2018, 6, 51. [CrossRef]

2. Evtugyn, G.; Hianik, T. Electrochemical Immuno- and Aptasensors for Mycotoxin Determination. Chemosensors 2019, 7, 10. [CrossRef]

3. Shimizu, F.M.; Braunger, M.L.; Riul, A., Jr. Heavy Metal/Toxins Detection Using Electronic Tongues. Chemosensors 2019, 7, 36. [CrossRef]

4. Johnson, A.D.; Curtis, R.M.; Wallace, K.J. Low Molecular Weight Fluorescent Probes (LMFPs) to Detect the Group 12 Metal Triad. Chemosensors 2019, 7, 22. [CrossRef]

5. Kuchmenko, T.A.; Lvova, L.B. A Perspective on Recent Advances in Piezoelectric Chemical Sensors for Environmental Monitoring and Foodstuffs Analysis. Chemosensors 2019, 7, 39. [CrossRef]

6. Tan, R.X.; Ibsen, M.; Tjin, S.C. Optical Fiber Refractometer Based Metal Ion Sensors. Chemosensors 2019, 7, 63. [CrossRef]

7. Khaydukova, M.; Militsyn, D.; Karnaukh, M.; Grüner, B.; Selucký, P.; Babain, V.; Wilden, A.; Kirsanov, D.; Legin, A. Modified Diamide and Phosphine Oxide Extracting Compounds as Membrane Components for Cross-Sensitive Chemical Sensors. Chemosensors 2019, 7, 41. [CrossRef]

8. Kumar, A.; Kumar, A.; Sahoo, P.R.; Kumar, S. Colorimetric and Fluorescence-Based Detection of Mercuric Ion Using a Benzothiazolinic Spiropyran. Chemosensors 2019, 7, 35. [CrossRef]

9. Lukyanenko, K.A.; Denisov, I.A.; Sorokin, V.V.; Yakimov, A.S.; Esimbekova, E.N.; Belobrov, P.I. Handheld Enzymatic Luminescent Biosensor for Rapid Detection of Heavy Metals in Water Samples. Chemosensors 2019, 7, 16. [CrossRef]

(C) 2020 by the author. Licensee MDPI, Basel, Switzerland. This article is an open access article distributed under the terms and conditions of the Creative Commons Attribution (CC BY) license (http://creativecommons.org/licenses/by/4.0/). 